\title{
ПОВТОРНОЕ КОРОНАРНОЕ ШУНТИРОВАНИЕ МИОКАРДА НА РАБОТАЮЩЕМ СЕРДЦЕ У ПАЦИЕНТА С ОСТРЫМ КОРОНАРНЫМ СИНДРОМОМ (КЛИНИЧЕСКИЙ СЛУЧАЙ)
}

\section{REDO CORONARY BYPASS INFARCTION AFTER ACUTE CORONARY SYNDROME IN THE WORKING HEART}

\section{A. Jalilov}

Summary. Currently, the operation of coronary artery bypass grafting is undoubtedly a highly effective method of treating patients with coronary artery disease. This method of myocardial revascularization in most cases allows achieving a stable improvement in the quality and an increase in the life expectancy of operated patients [1]. After primary myocardial revascularization, the likelihood of a patient requiring repeated coronary artery bypass grafting depends on patient-related indicators, indicators associated with primary surgery, the possibility of alternative treatment, expert opinion on the possibility of repeated myocardial revascularization and the time of its implementation [2]. The time of occurrence of relapse of angina pectoris is determined by the peculiarities of the clinic before the primary surgery, the presence or absence of post infarction cardiosclerosis, the prevalence and localization of stenosing lesions of the coronary arteries, concomitant pathology (arterial hypertension, dyslipidemia, diabetes mellitus, obesity II — III degree, etc.). Persistence of signs of instability before surgery, early post infarction angina pectoris, circulatory failure significantly worsen the prognosis of CABG [3]. The likelihood of a poor prognosis increases as the left ventricular ejection fraction decreases. Patients with acute coronary syndrome who have undergone myocardial revascularization and who are candidates for reoperation are increasing every year]. According to Research at the Cleveland Clinic, in the early years of coronary surgery (1967 to 1978), only $28 \%$ of patients underwent a second coronary bypass surgery solely for shunt thrombosis, and that shunt thrombosis often occurred early after primary surgery (mean postoperative interval 28 months after primary surgery). From 1967 to 1978, 55\% of patients operated on for coronary artery disease were repeatedly subjected to coronary artery bypass grafting due to the progression of atherosclerosis in non-bypass coronary arteries. Today, early graft damage and disease progression in unshunted vessels are not the main reasons for reoperation. Patients who have undergone reoperation have special, more complex pathologies. Atherosclerosis of venous shunts is present in most patients and is one of the leading and most dangerous diseases of conduits. The first case of successful repeated myocardial revascularization in a patient with recurrent angina pectoris after previously performed mammary-coronary bypass grafting is presented to our attention. Authors' contributions.

Keywords: acute coronary syndrome, coronary artery bypass grafting, repeated myocardial revascularization.

\author{
Жалилов Адхам Кахрамонович \\ К.м.н., Каршинский филиал республиканского \\ специализированного научно-практического \\ медицинского центра кардиологии \\ Jalilov_adham@mail.ru
}

Аннотация. В настоящее время операция аортокоронарного шунтирования, несомненно, является высокоэффективным методом лечения больных ИБС. Данный способ реваскуляризации миокарда, в большинстве случаев, позволяет добиться стойкого улучшения качества и увеличения продолжительности жизни оперированных пациентов [1].

После проведение первичной реваскуляризации миокарда риск повторной операции зависит от: показателей, связанных с пациентом, факторов, связанных с первичной операцией, возможности альтернативного лечения, мнения экспертов о возможности выполнения повторной реваскуляризации миокарда и времени ее выполнения [2].

Время возникновения рецидива стенокардии обусловлено особенностями клиники ИБС до первичного оперативного вмешательства, наличием или отсутствием постинфарктного кардиосклероза, распространенностью и локализацией стенозирующего поражения коронарных артерии, сопутствующей патологией (артериальная гипертензия, дислипидемия, сахарный диабет, ожирение II - III степени и др.). Сохранение признаков нестабильности стенокардии перед операцией, ранняя постинфарктная стенокардия, недостаточность кровообращения значительно ухудшают прогноз КШ [3]. Вероятность неблагоприятного прогноза возрастает по мере снижения фракции выброса левого желудочка.

Число пациентов с острым коронарным синдромом, перенесших реваскуляризацию миокарда и являющихся кандидатами на повторную операцию, увеличивается с каждым годом. Данные исследования, проведенного в Кливлендской клинике, наглядно продемонстрировали, что в ранние годы коронарной хирургии (с 1967 по 1978) только 28\% пациентов подверглись повторной операции — коронарному шунтированию, исключительно из-за тромбоза шунта, и что тромбоз шунта часто происходило в ранний период после первичной операции (средний послеоперационный интервал 28 месяцев после первичной операции). ( 1967 по 1978 г у $55 \%$ пациентов, оперированных по поводу ИБС, повторно подвергались коронарному шунтированию из-за прогрессирования атеросклероза в не шунтированных коронарных артериях. Сегодня раннее повреждение шунтов и прогрессирование болезни в нешунтированных сосудах не являются основными причинами повторной операции.

Пациенты, подвергшиеся повторной операции, имеют особые, более сложные патологии. Атеросклероз венозных шунтов присутствует у большинства больных и является одной из ведущих и опаснейших заболе- 


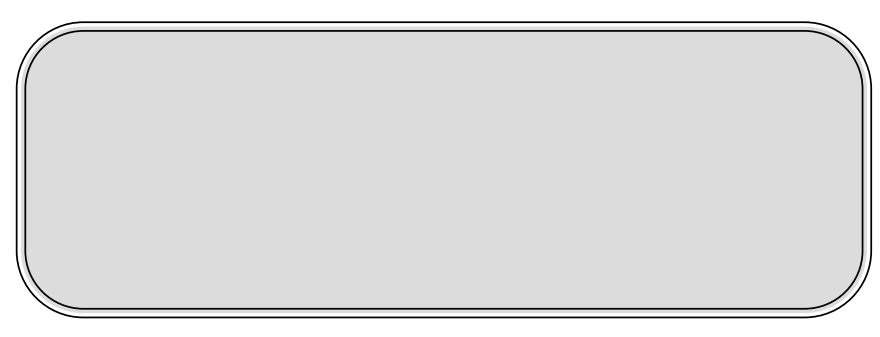

\section{Вве $е$ ение}

B настоящее время операция аортокоронарного шунтирования, несомненно, является высокоэффективным методом лечения больных ИБС. Данный способ реваскуляризации миокарда в большинстве случаев позволяет добиться стойкого улучшения качества и увеличения продолжительности жизни оперированных пациентов [1].

После проведение первичной реваскуляризации миокарда риск повторной операции зависит от: показателей, связанных с пациентом, факторов, связанных с первичной операцией, возможности альтернативного лечения, мнения экспертов о возможности выполнения повторной реваскуляризации миокарда и времени ее выполнения [2].

С ростом количества больных, подвергшихся операции аорто - коронарного шунтирования (АКШ), растет число пациентов, нуждающихся в повторной реваскуляризации миокарда (РМ); и, в настоящее время, по численности они составляют вторую после первичного аорто-коронарного шунтирования (АКШ) группу, нуждающихся в хирургическом лечении [1; 7].

Поражение атеросклерозом коронарных артерий $(\mathrm{KA})$, нестабильная стенокардия и прогрессирующая стенокардия, по своей природе имеют прогрессирующее течение. При этом шунтирующие кондуиты, в частности венозные, имеют тенденцию к атеросклеротическому поражению [1; 10]. Вышеперечисленные особенности способствуют рецидиву появления симптомов нестабильной стенокардии, инфаркта миокарда без подъёма сегмента ST и необходимости выполнения повторных вмешательств.

Потребность в повторном вмешательстве более часто возникает во 2-е десятилетие после первичной операции. По результатам исследовательской группы Sergeant, выявлено, что если спустя 10 лет после АКШ, повторного вмешательства удается избежать $89 \%$ пациентов, то через 15 лет этот показатель снижается до 72\% [4].

В нашем центре впервые выполнена повторная реваскуляризация миокарда на работающем сердце по методике off pump coronary artery bypass. ваний кондуитов. Вашему вниманию представляется первый случай успешного проведения повторной реваскуляризации миокарда у больной С возвратом стенокардии после ранее выполненного маммарокоронарного шунтирования.

Ключевые слова: острый коронарный синдром, аортокоронарное шунтирование, повторная реваскуляризация миокарда.

В нашей работе мы представляем первый опыт проведения повторной реваскуляризации миокарда на работающем сердце.

\section{Клинический случай}

Пациент К., 46 лет, поступил в стационар с диагнозом: ишемическая болезнь сердца. Нестабильная стенокардия. Постинфарктный кардиосклероз. Состояние после операции маммарокоронарное шунтирование от 2009 г. Гипертоническая болезнь III ст. Риск 4.

Из анамнеза известно, что в 2006 и 2007 годах перенес инфаркт миокард. В 2009 году после безуспешной попытки реканализации передней нисходящей артерии, было проведено маммарокоронарное шунтирование.

На момент госпитализации общее состояние средней тяжести. На ЭКГ - синусовая аритмия, признаки гипертрофии левого желудочка. Рубцовые изменения на задней стенке ЛЖ. По данным эхокардиографии: конечный диастолический объем 135 мл, конечный систолический объем 67 мл, фракция выброса левого желудочка 50\%. Размер левого предсердия не превышал 3,8 cм. Патологии клапанов сердца не выявлено. При коронарографии (Рис 1.): ствол левой коронарной артерии без изменений. Хроническая окклюзия в средней трети передней нисходящей артерии. Также имеется стеноз 85\% диагональной артерии и $65 \%$ артерии тупого края. Пациенту ранее были выполнены неоднократные безуспешные попытки реканализации коронарных артерий в разных клиниках республики и зарубежном. Учитывая тяжелое многососудистое поражение коронарных артерий и нестабильную стенокардию, решено провести повторную реваскуляризацию миокарда на работающем сердце.

Протокол операции: Установлен катетер в левую лучевую артерию пункционно. Эндотрахеальный наркоз. Операционное поле обработано раствором Бетадина троекратно. Срединная стернотомия. Левая внутренняя грудная артерия (ЛВГА) скелетизирована и мобилизирована от подключичной вены до бифуркации. Произведен забор V. saphena magna sinistra из расчета на 2 шунта. Перикард вскрыт, взят на дер- 
жалки. Введено 10000 ЕД гепарина. Экспозиция ПМЖВ В д/3. Артерия диаметром 1.5 мм. Силиконовый турникет дистальнее и проксимальнее артериотомии. Наложен дистальный анастомоз ЛВГА с ПМЖВ нитью пролен 8/0. Ревизия ВТК-1, ВТК-3, стенки артерии атеросклеротически изменены на всем протяжении, твердая с бляшками, нешунтабельна. Экспозиция ДВ в с/3. Артерия диаметром 2.25 мм. Силиконовый турникет дистальнее и проксимальнее артериотомии. Наложен дистальный анастомоз аутовены с артерии ДВ нитью пролен 7/0. На пристеночно отжатой аорте наложен проксимальный анастомоз аутовены с восходящей аортой нитью пролен 6/0. Профилактика воздушной эмболии. Пущен кровоток по шунту (Рис 2). Стабилизация гемодинамики. Послеоперационный период протекал гладко. Общая продолжительность вентиляции легких составила 8 часов. Пациент был выписан 12 -е сутки после операции в удовлетворительном состоянии.

\section{Обсужление}

После первично выполненной операции АКШ, вероятность повторного вмешательство, во многом, зависит как от хирургического пособия, так и от состояния нативных сосудов [3; 6].

Причиной рецидива стенокардии после операции АКШ в 83.8\% случаев является нарушение проходимости аортокоронарных шунтов, причем в 59,5\% случаев - это единственная причина возобновления ангинозных приступов [6]. Частота других причин рецидива стенокардии после АКШ была выявлена в следующих пределах:

- прогрессирование атеросклероза КА (шунтированных и нешунтированных) от 5,4 до 28,6\% случаев [11];

- неполная реваскуляризация (отдельная причина в комбинации с дисфункцией шунтов) - до 29,1\% [11];

- сочетанное поражение аутовенозного шунта и КА - от 2,7 до $11,9 \%$ [2; $9 ; 11]$.

По мнению Б.В. Шабалкина и Жбанова И.В. [2; 4], результаты АКШ во многом определяются функциональным состоянием участка «аорта- трансплантат-коронарная артерия». При этом авторы считают, что для нормального функционирования необходимо выполнять ряд требований: 1 - правильно наложить анастомозы; 2 - выбрать соответствующую длину трансплантата; 3 - правильно расположить трансплантат между аортой и коронарной артерией. Повторное АКШ сопровождается более высокой частотой осложнений и летальности по сравнению с первичным вмешательством. Среди таких осложнений выделяют: трудности с доступом; опасность повреждения миокарда и функционирующих шунтов при кардиолизе; эмболизация атероматозными массами от пораженных кондуитов, трудности поиска последних; проблемы обеспечения адекватной защиты миокарда [7; 9; 13]. Поражение атеросклерозом коронарных артерий (КА), нестабильная стенокардия и прогрессирующая стенокардия по своей природе имеет прогрессирующее течение. При этом шунтирующие кондуиты, в частности венозные, имеют тенденцию к атеросклеротическому поражению $[1 ; 10]$. Вышеперечисленные особенности способствуют рецидив появления симптомов нестабильной стенокардии, инфаркта миокарда без подъёма ST и необходимость выполнения повторных вмешательств.

Потребность в повторном вмешательстве более часто возникает во 2-е десятилетие после первичной операции. По результатам исследовательской группы Sergeant выявлено, что если спустя 10 лет после АКШ, повторного вмешательства удается избежать 89\% пациентов, то через 15 лет этот показатель снижается до $72 \%$ [4].

При проведении повторного коронарного шунтирования в $60 \%$ случаев осложнения развиваются на этапе выполнения стернотомии и кардиолиза [7; 10]. После стернотомии развитие катастрофических кровотечений составляет от $2 \%$ до $6 \%$ со смертностью до $37 \%$ [7; 10], при этом повреждение мамарной артерии отмечается от $10 \%$ до $30 \%$ случаев, с дальнейшим развитием острого инфаркта миокарда до $20 \%$ и летальностью до $60 \%$ [7].

Повторное проведение коронарного шунтирования на работающем сердце по методике малоинвазивной реваскуляризации миокарда является одним из важных факторов успеха вмешательства вместе с высоко профессиональной кардиокомандой [8; 12]. По данным Ногзе и соавт., из 548 повторно оперированных больных на работающем сердце 514 (94\%) пациентов были экстубированы на операционном столе [9; 13].

Таким образом, большинство рандомизированных исследований показали существенное уменьшение у повторно оперированных больных на работающем сердце по сравнению с повторно оперированными больными с ИК следующих показателей: потребности трансфузии препаратов крови, инотропной поддержки, респираторных инфекций, фибрилляций предсердий, острых нарушений кровообращения мозга (ОНМК), инфарктов миокарда, медиастинитов и рецидивов стенокардии в ближайшем послеоперационном периоде (до 30 дней) и летальности, как в ближайшем, так и в отдаленном послеоперационном периоде. 

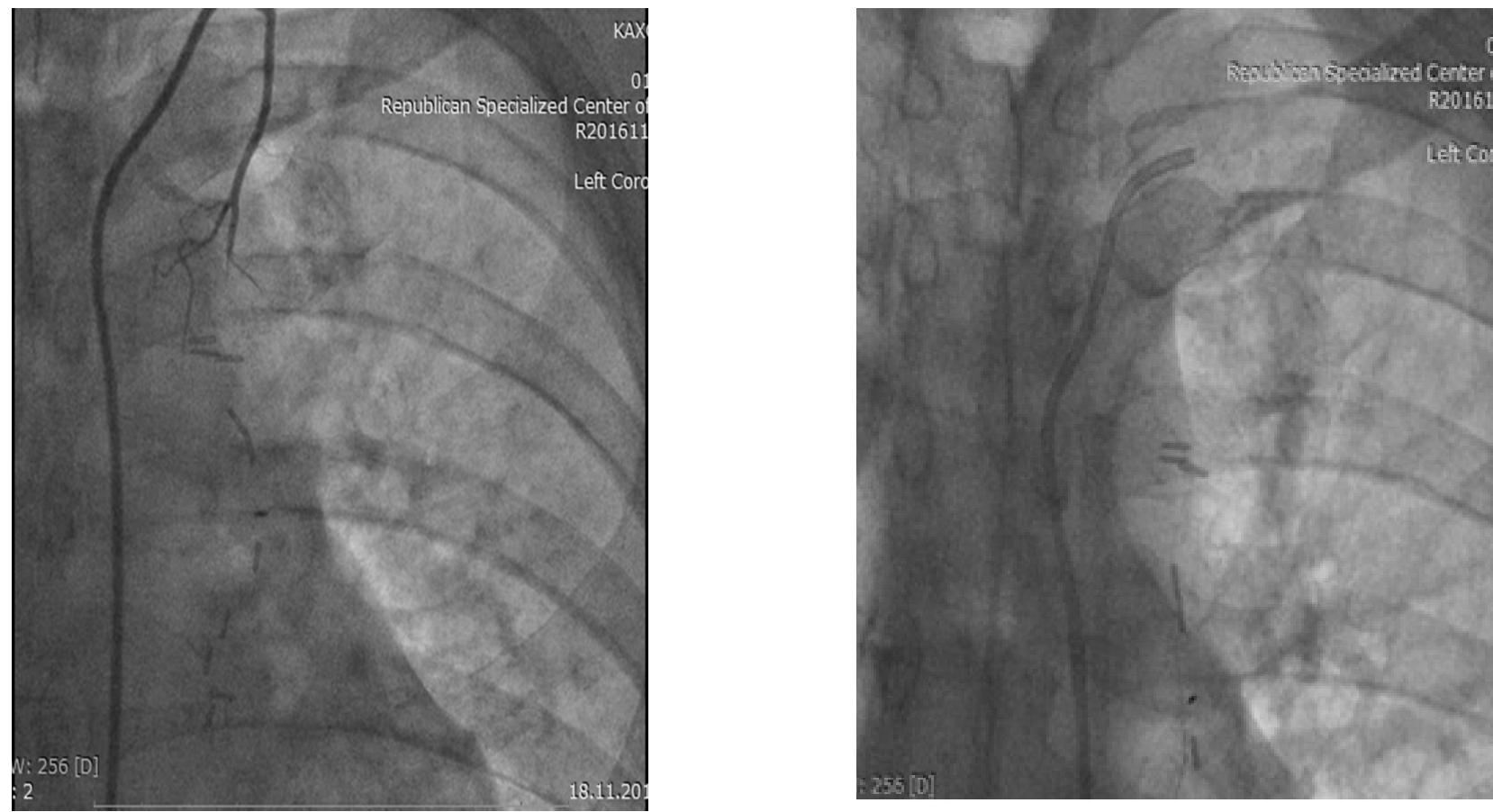

Рис. 1. Ангиография коронарных артерии и маммарокоронарного шунта. Обозначен тотальный стеноз левой внутренней грудной артерии с передней межжелудочковой ветвью

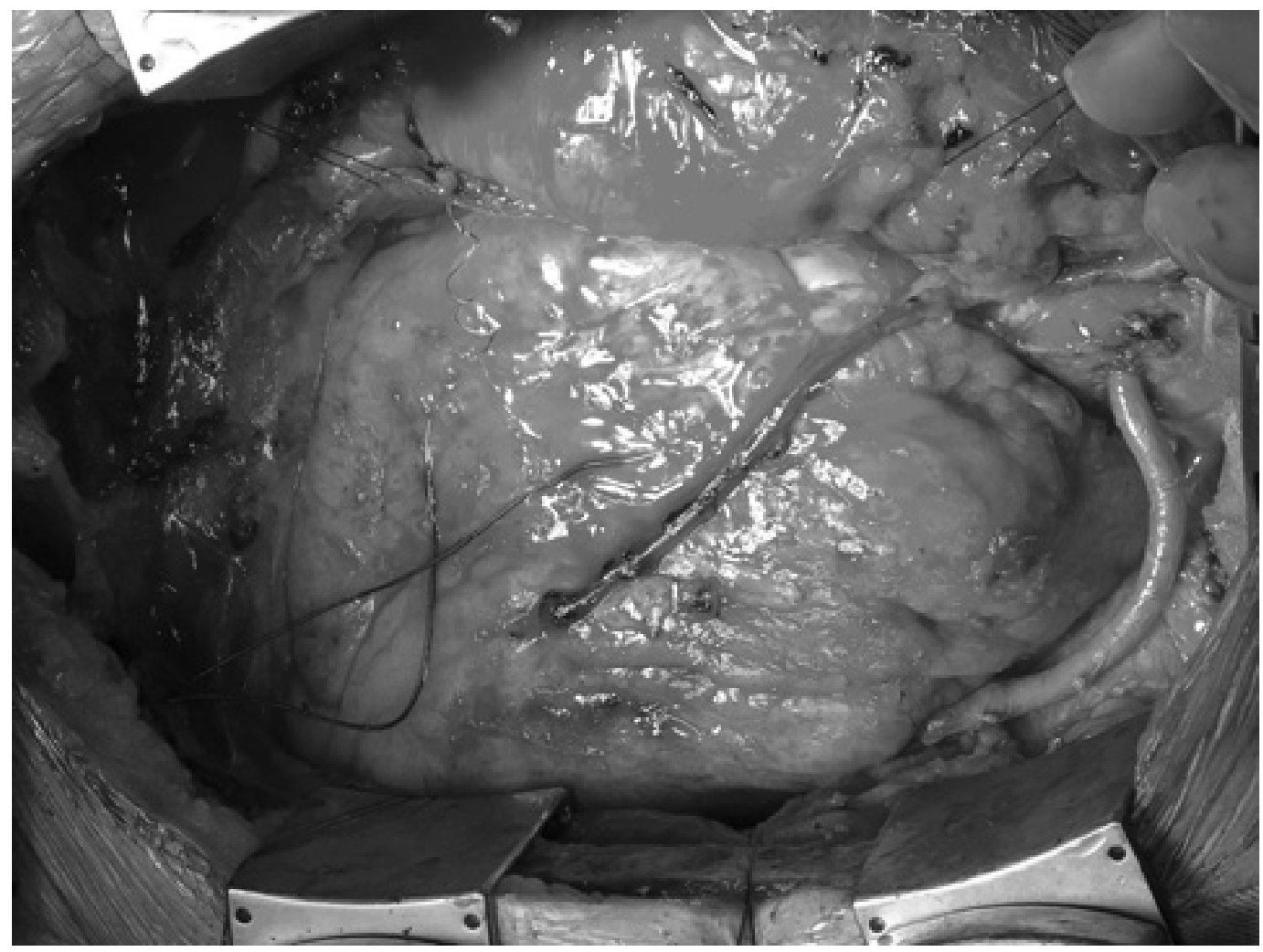

Рис. 2. Интраоперационное фото. Проведена операция - повторная малоинвазивной реваскуляризации миокарда доступом через срединную рестернотомию. Выполнено маммарнокоронарное шунтирование передней межжелудочковой артерии и аортокоронарное шунтирование аутовенозным трансплантатом диагональной ветви) 


\section{ЛИТЕРАТУРА}

1. Бокерия Л.А., Беришвили И.И., Сигаев И.Ю. Минимально инвазивная реваскуляризация миокарда у больных ИБС. - 2001 г.

2. Жбанов И.В. Повторная реваскуляризация миокарда при рецидиве стенокардии после аортокоронарного шунтирования. Дисс... докт. мед. наук. -M., - 1999.-P. 218 C.

3. Сигаев И.Ю., Казарян А.В., Старостин М.В., Морчадзе Б.Д. Повторная реконструкция дистального маммарокоронарного анастомоза с ПМЖВ через левосторонюю переднебоковую торакотомию. // Патология кровообращения и кардиохирургия.-2015.—vol.4 -P. 130-133.

4. Шабалкин Б.В., Жбанов И.В., Минкина С.М., Абугов С.А. «Болезнь» аутовенозных трансплантатов - основная причина рецидива стенокардии после аортокоронарного шунтирования. // Грудная и сердечно-сосудистая хирургия. — 1999. — vol 5. — P. 20.

5. Bergsland J, Hasnain S, Lajos TZ, Salerno TA Elimination of cardiopulmonary bypass: a prime goal in reoperative coronary artery bypass surgery. Eur J Cardiothorac Surg. - 1998. - Vol 14.-P. 59-62

6. Czerny M, Zimpfer D, Kilo J, Gottardi R, Dunkler D, Wolner E, Grimm M Coronary reoperations: recurrence of angina and clinical outcome with and without cardiopulmonary bypass. Ann Thorac Surg — 2003. -vol 75.-P. 847-852

7. Machiraju V.R. How to avoid problems in redo coronary artery bypass surgery. J Card Surg. — 2014. — vol 19. —P. 284-290

8. Mishra YK, Collison SP, Malhotra R, Kohli V, Mehta Y, Trehan N Ten-year experience with single-vessel and multivessel reoperative off-pump coronary artery bypass grafting. J Thorac Cardiovasc Surg. - 2008. — vol.135 — P. 527-532

9. Morris CD, Puskas JD, Pusca SV, Lattouf OM, Cooper WA, Vassiliades TA, Chen EP, Thourani VH, Kilgo PD, Guyton RA Outcomes after off-pump reoperative coronary artery bypass grafting. Innovations. - 2007. - vol 2. - P 29-32

10. Stamou SC, Pfi ster AJ, Dangas G, Dullum MK, Boyce SW, Bafi AS, Garcia JM, Corso PJ Beating heart versus conventional single-vessel reoperative coronary artery bypass. Ann Thorac Surg -2019. — vol 69. - P. 1383-1387

11. Schutz A, Mair H, Wildhirt SM, Gillrath G, Lamm P, Kilger E, Reichart B Re-OPCAB vs. Re-CABG for myocardial revascularization. Thorac Cardiovasc Surg. — 2010. — vol. 49 - P. $144-148$

12. Vohra HA, Bahrami T, Farid S, Mafi A, Dreyfus G, Amrani M, Gaer JA Propensity score analysis of early and late outcome after redo off-pump and on-pump coronary artery bypass grafting. Eur J Cardiothorac Surg. - 2008. - vol. 33 -P. 209-214

13. Yau TM, Borger MA, Weisel RD, Ivanov J The changing pattern of reoperative coronary surgery: trends in 1230 consecutive reoperations. J Thorac CardiovascSurg. - 2000. - vol. 120 - P. 156-163

( Ж Жалилов Адхам Кахрамонович ( Jalilov_adham@mail.ru ).

Журнал «Современная наука: актуальные проблемы теории и практики» 